\title{
Comportamento intra-específico do cupim Heterotermes tenuis (Hagen) (Isoptera, Rhinotermitidae) em condições de laboratório
}

\author{
Célia R.R. de Camargo-Dietrich ${ }^{1}$ \\ Ana Maria Costa-Leonardo ${ }^{1}$
}

\begin{abstract}
Intraspecific behavior of the termite Heterotermes tenuis (Hagen) (Isoptera, Rhinotermitidae) in laboratory conditions. Groups of Heterotermes tenuis (Hagen, 1858) from five infestation points were paired in bioassays to investigate the intercolony aggression. The combinations of arena sizes (Petri dishes of 6.0 and $9.0 \mathrm{~cm})$ and temperatures $\left(25\right.$ and $28^{\circ} \mathrm{C}$ ) were assessed for effects on intraspecific agonism. Agonistic behavior was scored positive in arena if more than half of the starting number of termites was dead and injured after 17 hours. After the intraspecific encounters it was possible to delimitate three colonies from the five infestation points. No significant differential survival was seen in two different arena sizes and two different temperatures. These assays indicate that the factors governing the agonistic behavior in $H$. tenuis are complex and seems to be dependent on environmental conditions and individual characteristics (age, size and caste).

KEY WORDS. Isoptera, Rhinotermitidae, Heterotermes tenuis, intraspecific behavior
\end{abstract}

A espécie nativa Heterotermes tenuis (Hagen, 1858) é subterrânea, formada por cupins de pequeno porte e apresenta soldados dimórficos (CONSTANTINO 1991). Em ambientes naturais, geralmente $H$. tenuis é encontrado em madeira com um certo grau de decomposição. Contudo, a espécie já foi descrita atacando colmo de milho envelhecido, Eucalyptus vivo, cana-de-açúcar e também livros e jornais em meio urbano (ARAÚJO 1958, 1986; PIZANO \& FONTES 1986; MiLl 1991). Este cupim não constrói ninhos conspícuos e individualizados, mas pode ser encontrado em ninhos abandonados de outras espécies (BANDEIRA 1985).

$\mathrm{Na}$ cidade de Rio Claro (São Paulo), a referida espécie ocorre tanto em ambientes agrícolas como no meio urbano. $\mathrm{O}$ hábito críptico deste inseto limita os estudos de biologia e, por este motivo, existem poucos trabalhos referentes ao mesmo.

Os cupins podem defender intra ou interespecificamente os seus territórios de forrageio (JONES \& TROSSET 1991). As interações intra-específicas podem ser passivas ou agonísticas. $\mathrm{O}$ comportamento agonístico refere-se às interações sociais de ataque e resposta às agressões que ocorrem quando insetos de diferentes espécies ou colônias se encontram (GRACE 1996). A intensidade dos encontros agonísticos depende da espécie, da colônia, das castas envolvidas e de fatores ambientais, como por exemplo as estações do ano, que podem influenciar o padrão de comportamento do indivíduo (CLÉMENT 1986; THORNE \& HAVERTY 1991).

1) Departamento de Biologia, Universidade Estadual Paulista. Caixa Postal 199, 13506-900 Rio Claro, São Paulo, Brasil. E-mail: amcl@rc.unesp.br 
SPRINGHETTI \& SAPIGNI (1990) demonstraram a redução de agressividade seguida de trofalaxia entre as espécies Reticulitermes lucifugus (Rossi, 1792) (Rhinotermitidae) e Kalotermes flavicollis (Fabricius, 1949) (Kalotermitidae) quando estes cupins foram expostos a baixas temperaturas. SHELTON \& GRACE (1997a) também verificaram falta de agressividade em interações intercoloniais do cupim Coptotermes formosanus Shiraki, 1909 após acondicionamento por uma hora a uma temperatura de aproximadamente três graus Celsius.

Os mecanismos envolvidos nas respostas agressivas ainda não estão totalmente esclarecidos e os resultados observados nos bioensaios são muito variados (THORNE 1982; GRACE 1996). Apesar disso, o comportamento agonístico intra-específico tem sido usado em bioensaios para delimitar o território de forrageio das colônias de alguns cupins subterrâneos (THORNE \& HAVERTY 1991; JONES 1990, 1993). Esses bioensaios consistem no pareamento de indivíduos provenientes de colônias diferentes dentro de um recipiente, considerado como arena, para observação do comportamento agressivo após um período de interação.

Em vista do exposto acima, o objetivo deste trabalho foi avaliar a influência da variação da temperatura e do tamanho da arena no comportamento intra-específico do cupim H. tenuis, em condições de laboratório.

\section{MATERIAL E MÉTODOS}

Neste trabalho foram utilizados cupins forrageiros da espécie $H$. tenuis. Os indivíduos foram capturados em armadilhas de papelão corrugado colocadas no interior de uma sala do Biotério (ponto de infestação A; Fig. 1) e no lado externo do prédio da Biblioteca (pontos de infestação B, C, D e E; Fig. 1) do câmpus da Universidade Paulista (UNESP), Rio Claro, São Paulo.

O ponto de infestação A estava localizado a aproximadamente $340 \mathrm{~m}$ de distância dos pontos B, C e D e a $300 \mathrm{~m}$ do $\mathrm{E}$ (Fig. 1). Os pontos de infestação B, C e D estavam muito próximos $(1,5 \mathrm{~m})$ uns dos outros e a aproximadamente $50 \mathrm{~m}$ de distância do ponto E (Fig. 1).

Os bioensaios foram montados no dia 23/III/1999 com pareamentos entre os cupins provenientes dos diferentes pontos de infestação conforme a sequência: $\mathrm{A} x$ $\mathrm{B}, \mathrm{B} \times \mathrm{E}, \mathrm{D} \times \mathrm{E}, \mathrm{C} \times \mathrm{D}$. Por não haver um número suficiente de cupins, o pareamento A $\times$ E foi realizado posteriormente (27/IV/1999).

De cada ponto de infestação foram selecionados 10 operários e 1 soldado para os confrontos realizados. Devido a baixa proporção de soldados coletada nos grupos de forrageio, não foi possível escolher o tipo de soldado nos diversos pareamentos realizados. Os bioensaios foram montados em placas de Petri (arenas) de diferentes diâmetros $(6 \mathrm{~cm} \mathrm{e} 9 \mathrm{~cm})$ forradas com papel de filtro umedecido. Além disso, utilizou-se duas condições de temperatura, isto é, temperatura ambiente (aproximadamente $25^{\circ} \mathrm{C}$ ) e temperatura controlada em uma estufa bacteriológica (B.O.D.) $\left(28^{\circ} \mathrm{C}\right)$. Para cada pareamento foram testados os dois tamanhos de arena e as duas condições de temperatura, sendo que foram realizadas cinco repetições e dois grupos controles.

Os bioensaios foram mantidos no escuro por aproximadamente 17 horas. Após este período os indivíduos foram contados e observados sob estereomicroscópio para avaliação do comportamento agressivo. O comportamento agonístico 
intra-específico foi considerado positivo quando mais de $50 \%$ dos indivíduos estavam mortos e mutilados, ou seja, com as pernas ou antenas arrancadas, abdômen ferido e/ou cabeça decepada. A metodologia usada foi baseada em Polizzi \& FORSCHLER (1998) com modificação do tempo de interação de 24 para 17 horas, pois experiências prévias mostraram que quando ocorre agressividade, um tempo maior de interação ( 24 horas) facilita o aparecimento de fungos sobre os cupins mortos dificultando a observação das injúrias.

Nas interações onde foi constatado o comportamento agonístico, os cupins foram considerados como pertencentes a colônias diferentes. Os dados referentes à sobrevivência média entre os pareamentos foram submetidos a uma análise de variância fatorial (S.A.S. versão 6.12), considerando como fatores de variação o local (arenas de $6 \mathrm{~cm}$ e $9 \mathrm{~cm})$ e temperatura $\left(25\right.$ e $\left.28{ }^{\circ} \mathrm{C}\right)$.

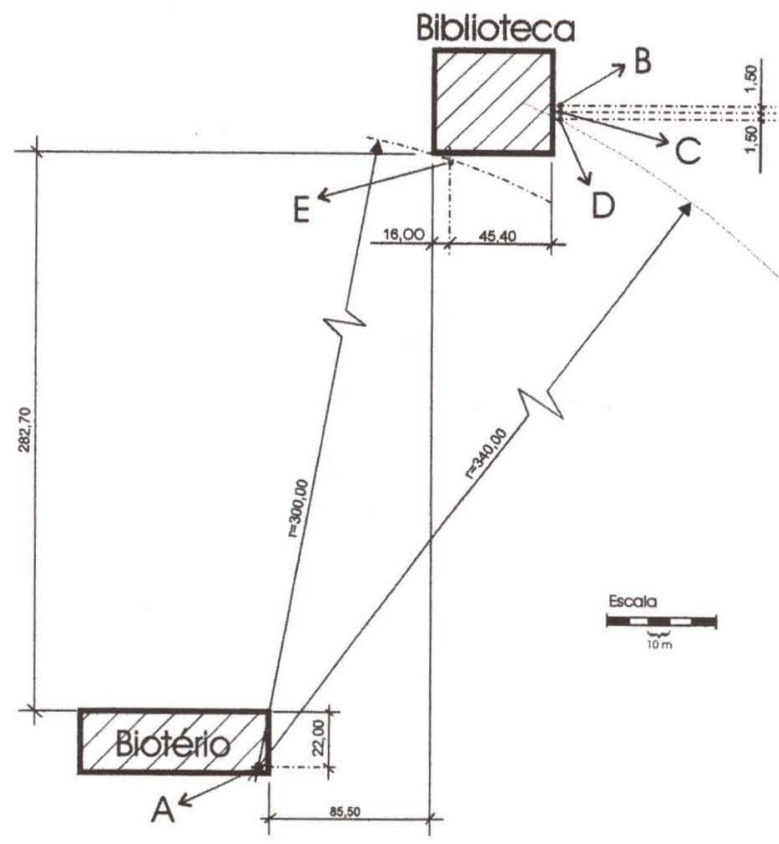

Fig. 1. Representação dos pontos de infestação e da distância entre os mesmos. (A) Biotério, (B-E) Biblioteca.

\section{RESULTADOS}

$\mathrm{Na}$ tabela I estão incluidos os resultados obtidos nas interações intra-específicas de $H$. tenuis em relação a variação do tamanho da arena e da temperatura.

A mortalidade após as diversas interações agonísticas realmente refletiu o grau de agressividade apresentado pelos indivíduos. Em todas as interações agonísticas foi verificado que os indivíduos morreram devido às injúrias, sendo que muitos estavam decapitados. 
Os pareamentos A x B, B x E e D x E realizados nas diferentes condições de temperatura e de tamanho de arena resultaram em respostas agressivas, com alta taxa de mortalidade (Tab. I) e indivíduos muito mutilados.

As interações $\mathrm{A} \times \mathrm{E}$ e C $\mathrm{x}$ D não foram agressivas em nenhuma das condições testadas pois, a taxa de sobrevivência nestes pareamentos foi alta (Tab. I) e não foi constatada a presença de indivíduos machucados.

Tabela I. Porcentagem média de sobrevivência $( \pm D P)$ de Heterotermes tenuis após encontros intra-específicos realizados em arenas de $6 \mathrm{~cm}(\mathrm{~A} 1)$ e $9 \mathrm{~cm}(\mathrm{~A} 2)$ sob temperaturas de $25^{\circ} \mathrm{C}$ (T1) e $28^{\circ} \mathrm{C}$ (T2). Ponto de infestação. Pontos de infestação (A) Biotério, (B-E) Biblioteca.

\begin{tabular}{|c|c|c|c|c|c|c|}
\hline \multirow{2}{*}{ Pareamentos } & \multirow{2}{*}{ Repetiçőes - } & \multicolumn{4}{|c|}{ Porcentagem de sobrevivência \pm Desvio padrăo } & \multirow{2}{*}{ Valores de F * } \\
\hline & & $\mathrm{A} 1 \mathrm{e} \mathrm{T} 1$ & $\mathrm{~A} 2 \mathrm{e} \mathrm{T} 1$ & $\mathrm{~A} 1 \mathrm{e} \mathrm{T} 2$ & $\mathrm{~A} 2 \mathrm{e} \mathrm{T} 2$ & \\
\hline$A \times B$ & 5 . & $33,6 \pm 6,14+$ & $25,4 \pm 9,28+$ & $28,1 \pm 15,54+$ & $20,0 \pm 6,91+$ & 2,41 \\
\hline$B \times E$ & 5 & $29,0 \pm 16,29+$ & $49,0 \pm 31,44+$ & $26,3 \pm 12,64+$ & $41,0 \pm 24,25+$ & 1,75 \\
\hline$D \times E$ & 5 & $28,1 \pm 16,21+$ & $39,0 \pm 16,56+$ & $29,0 \pm 33,64+$ & $37,2 \pm 32,51+$ & 0,36 \\
\hline$A \times E$ & 5 & $92,6 \pm 6,11-$ & $89,1 \pm 17,22-$ & $88,2 \pm 11,86-$ & $84,0 \pm 21,62-$ & 0,65 \\
\hline$C \times D$ & 5 & $88,1 \pm 8,26-$ & $92.7 \pm 5,17-$ & $93,6 \pm 6,89-$ & $80,0 \pm 5,17-$ & 1,32 \\
\hline
\end{tabular}

$(+)$ comportamento agonistico positivo; $(-)$ comportamento agonístico negativo; $\left({ }^{\star}\right)$ valor tabelado de $\mathrm{F}$ a $5 \%=3,59$.

Nos controles, nos quais foram pareados indivíduos provenientes do mesmo ponto de infestação, foi verificada uma alta taxa de sobrevivência (Tab. II) nas diferentes condições de temperatura e de tamanho de arena. Nos controles onde a sobrevivência foi inferior a $100 \%$ os indivíduos nunca estavam mutilados. Em todas as interações agonísticas a sobrevivência foi menor que $100 \%$ e os indivíduos estavam muito mutilados.

Tabela II. Porcentagem média de sobrevivência de Heterotermes tenuis nos controles realizados em arenas de $6 \mathrm{~cm}$ (A1) e $9 \mathrm{~cm}$ (A2) sob temperaturas de $25^{\circ} \mathrm{C}$ (T1) e $28^{\circ} \mathrm{C}$ (T2). Ponto de infestação (A) Biotério, (B-E) Biblioteca.

\begin{tabular}{crrrr}
\hline \multirow{2}{*}{ Pareamentos } & \multicolumn{4}{c}{ Porcentagem de sobrevivência } \\
\cline { 2 - 5 } & A1 e T1 & A2 e T1 & A1 e T2 & A2 e T2 \\
\hline A X A & 100,0 & 100,0 & 97,7 & 100,0 \\
B B & 84,1 & 88,6 & 95,5 & 95,5 \\
C X C & 100,0 & 86,4 & 100,0 & 86,4 \\
D X D & 77,2 & 100,0 & 100,0 & 86,3 \\
ExE & 100,0 & 97,7 & 100,0 & 98,7 \\
\hline
\end{tabular}

Tanto nas interações agonísticas como nas passivas, não foram observadas diferenças significativas na porcentagem média de sobrevivência em relação aos tamanhos de arena e temperaturas testados (Tab. I).

\section{DISCUSSÃO}

Pelos resultados de agressividade obtidos nas interações intra-específicas pode-se concluir que os cupins coletados no ponto de infestação A (Biotério) pertencem a uma colônia diferente daqueles coletados no ponto de infestação B 
(Biblioteca). Este resultado era esperado, uma vez que os referidos locais distam entre si cerca de $340 \mathrm{~m}$. Por outro lado, os resultados das interações entre os diversos pontos da Biblioteca indicaram a presença de duas colônias distintas, uma localizada nos pontos B e D e outra no ponto E. Como os pontos de infestação B, C e D estavam localizados muito próximos entre si $(1,5 \mathrm{~m})$ e a interação $\mathrm{C} \times \mathrm{D}$ resultou em alta taxa de sobrevivência, é evidente que os cupins coletados nestes pontos fazem parte de uma única colônia. Portanto, através dos testes intra-específicos foi possível delimitar três colônias de $H$. tenuis a partir dos cinco pontos de infestação iniciais.

$\mathrm{O}$ resultado da interação $\mathrm{A} x \mathrm{E}$ não foi o esperado, pois não houve comportamento agonístico entre os cupins testados, apesar da grande distância entre os referidos pontos. Como este pareamento foi realizado posteriormente, é provável que fatores ambientais da própria colônia, na época da coleta, tenham influenciado o comportamento destes cupins, mesmo considerando que os testes laboratoriais tenham sido realizados nas mesmas temperaturas de 25 e $28^{\circ} \mathrm{C}$. De acordo com CLÉMENT (1986), o comportamento de agressividade das colônias de cupins pode variar durante diferentes épocas do ano. Outra explicação para este resultado pode estar na escolha dos indivíduos envolvidos no pareamento, ou seja, o comportamento agonístico dos operários pode estar delegado a indivíduos específicos dentro da colônia. De acordo com Polizzi \& ForSCHLER (1998), este pode ser um exemplo de polietismo entre os membros da casta de operários.

De acordo com THORNE (1982), a casta de operários também é responsável pela defesa nos encontros intra e interespecíficos porque eles são numericamente dominantes nas colônias. Já JONES (1993), observando o comportamento de agressividade de colônias naturais de Heterotermes aureus (Snyder, 1920), sugeriu que os soldados são mais importantes do que os operários como casta defensiva. No entanto, nos testes laboratoriais, a mesma pesquisadora observou comportamento agressivo em grupos constituídos somente por operários de diferentes colônias de H. aureus. No presente trabalho, utilizou-se nos testes laboratoriais as duas castas, operários e soldados, por ser esta uma situação mais condizente em relação às condições naturais de uma colônia de $H$. tenuis. Contudo, a casta de soldado em $H$. tenuis é dimórfica, e não existe estudo sobre a função de cada uma delas dentro da colônia, embora acredite-se que os dois tipos de soldados, pequeno e grande estejam engajados na defesa da colônia.

Os dois tamanhos de arenas testados não influenciaram o comportamento agonístico intra-específico de $H$. tenuis. Resultado semelhante foi observado por POLIZZI \& FORSCHLER (1998) em testes interespecíficos com Reticulitermes flavipes (Kollar) e Reticulitermes virginicus (Banks, 1907), os quais usaram os mesmos tamanhos de arena. As duas condições de temperatura testadas também não influenciaram o comportamento agonístico intra-específico, provavelmente pelo fato da variação não ser muito grande. SHELTON \& GRACE (1997a) demonstraram que houve uma redução do comportamento de agressividade quando cupins da espécie Coptotermes formosanus, antes dos pareamentos, foram mantidos em baixas temperaturas. Para os autores, a baixa temperatura suprimiu alguns fatores de reconhecimento dos companheiros de ninho. De acordo com alguns pesquisadores (NEL 1968; CLÉMENT 1986; SHELTON \& GRACE 1997b), a diminuição do comportamento 
agressivo pode estar ligada a uma longa permanência destes insetos no laboratório, antes da realização dos bioensaios. Este fato não ocorreu no presente estudo pois os indivíduos utilizados foram coletados pouco antes da realização dos testes.

Estes resultados sugerem que apesar das condições do laboratório serem artificiais, nos dois parâmetros testados (arena e temperatura), o comportamento agonístico de $H$. tenuis praticamente não foi afetado. Os resultados indicam que os fatores que governam o comportamento de agressividade são muito complexos e parecem depender de características indivíduais (tamanho e idade das castas escolhidas para os pareamentos) e condições ambientais.

AGRADECIMENTOS. Os autores agradecem ao Dr. Antonio Carlos Simões Pião pela ajuda nas análises estatísticas, ao Dr. José Chaud-Netto pela leitura do manuscrito e ao CNPq pelo apoio financeiro.

\section{REFERÊNCIAS BIBLIOGRÁFICAS}

AraúJo, R.L. 1958. Contribuição à biogeografia dos térmitas de São Paulo, Brasil. Insecta-Isoptera. Arq. Inst. Biol., São Paulo, 25: 185-217.

ARAúJo, R.L. 1986. Térmitas prejudiciais às madeiras, p. 100-123. In: F.A.M. MARICONI; A.P.L. ZAMITH;

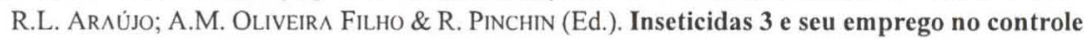
às pragas. Tomo III. São Paulo, Ed. Nobel, $2^{\mathrm{a}}$ ed., 246p.

Bandeira, A.G. 1985. Cupinzeiros como fonte de nutrientes em solos pobres da Amazônia. Bol. Mus. Paraense Emílio Goeldi, sér. Zool., 2 (1): 39-48.

CLÉMENT, J.L. 1986. Open and closed societies in Reticulitermes termites (Isoptera, Rhinotermitidae): Geographic and seasonal variations. Sociobiology 11 (3): 311-323.

Constantino, R. 1991. Termites (Isoptera) from the lower Japurá River, Amazonas State, Brazil. Bol. Mus. Paraense Emílio Goeldi, sér. Zool., 7 (2): 189-224.

GracE, J.K. 1996. Absence of overt agonistic behavior in a Northern population of Reticulitermes flavipes (Isoptera: Rhinotermitidae). Sociobiology 28 (1): 103-110.

JONES, S.C. 1990. Delineation of Heterotermes aureus (Isoptera: Rhinotermitidae) foraging territories in Sonoran desert grassland. Environ. Entomol. 19 (4): 1047-1054.

-1993. Field observations of intercolony aggression and territory changes in Heterotermes aureus (Isoptera: Rhinotermitidae). Jour. Ins. Behav. 6 (2): 225-236.

JoNES, S.C. \& M.W. TRosset. 1991. Interference competition in desert subterranean termites. Entomol. Exp. Appl. 61: 83-90.

MiLL, A. 1991. Termites as structural pests in Amazonia, Brazil. Sociobiology 19 (2): 339-348.

NEL, J.J.C. 1968. Aggressive behaviour of the harvester termites Hodotermes mossambicus (Hagen) and Trinervitermes trinervoides (Sjostedt). Insectes Soc. 15: 145-156.

PizAnO, M.A. \& L.R. FonTES. 1986. Ocorrência de Heterotermes tenuis (Hagen, 1858) e Heterotermes longiceps (Snyder, 1924) (Isoptera, Rhinotermitidae) atacando cana-de-açúcar no Brasil. Brasil Açucareiro, Rio de Janeiro, 104 (3/4): 29.

PolizzI, J.M. \& B.T. ForSCHLLR. 1998. Intra- and interspecific agonism in Reticulitermes flavipes (Kollar) and $R$. virginicus (Banks) and effects of arena and group size in laboratory assays. Insectes Soc. 45: 43-49.

Shelton, T.G. \& J.K. GRACE. 1997a. Impact of low temperature conditioning on intercolonial agonism in Coptotermes formosanus (Isoptera: Rhinotermitidae). Sociobiology 30 (2): 197-211.

-1997b. Suggestion of an environmental influence on intercolony agonism of Formosan subterranean termites (Isoptera: Rhinotermitidae). Environ. Entomol. 26: 632-637. 
Springhetti, A. \& T. Sapigni. 1990. Trophallaxis between Reticulitermes lucifugus and Kalotermes flavicollis (Isoptera). Sociobiology 17 (2): 245-258.

THORNE, B.L. 1982. Termite-termite interactions: workers as an agonistic caste. Psyche 89 (1-2): 133-150.

THORNE, B.L. \& M.I. HAVERTY. 1991. A review of intracolony, intraspecific, and interspecific agonism in termites. Sociobiology 19 (1): 115-145.

Recebido em 19.VIII.1999; aceito em 18.IV.2000. 